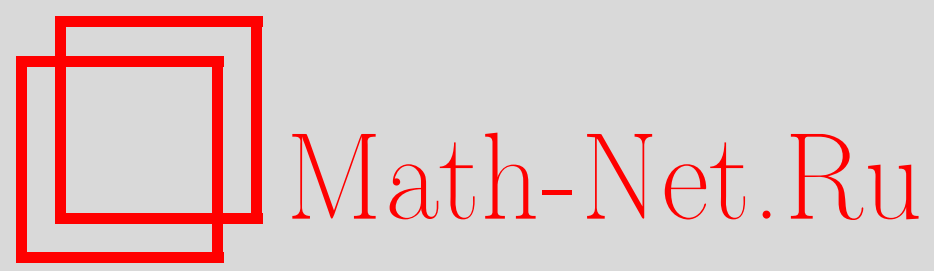

С. Н. Косинова, Решение задачи о затвердевании металлического расплава, Вестн. Сам. гос. техн. ун-та. Сер. Физ.-мат. науки, 2002, выпуск 16, 145148

DOI: https://doi.org/10.14498/vsgtu112

Использование Общероссийского математического портала Math-Net.Ru подразумевает, что вы прочитали и согласны с пользовательским соглашением

http://www. mathnet.ru/rus/agreement

Параметры загрузки:

IP: 54.81 .137 .203

26 апреля 2023 г., 16:12:27 


\section{С.Н. Косинова}

\section{РЕШЕНИЕ ЗАДАЧИ О ЗАТВЕРДЕВАНИИ МЕТАЛЛИЧЕСКОГО РАСПЛАВА}

Решена задача Стефана о затвердевании расплава. Найдены зависимости положения фронта кристаллизации и скорости его перемещения от времени, скорости кристаллизации от теплофизических параметров материала покрытия, скорости кристаллизации в двойных и тройных системах $\mathrm{Fe}-\mathrm{Ni}, \mathrm{Fe}-\mathrm{Cr}$, Fe-Ti, $\mathrm{Fe}$-V, $\mathrm{Fe}-\mathrm{W}, \mathrm{Fe}-\mathrm{Ni}-\mathrm{Cr}$, Fe-Ni-Ti, $\mathrm{Fe}-\mathrm{Ni}-\mathrm{V}, \mathrm{Fe}-\mathrm{Ni}-\mathrm{W}$ от процентного содержания компонентов. Построена физическая модель кристаллизации ванны расплава, полученной при воздействии лазерного и электронного лучей на материал покрытия.

Одной из важнейших задач материаловедения и физики твёрдого тела является создание новых материалов и управление процессом формирования их структуры и свойств. Широкие возможности в этом направлении открываются в использовании современных методов модифицирования уже существующих материалов. Так методы модифицирования материалов с использованием концентрированных потоков энергии составляют одно из наиболее перспективных направлений современного материаловедения. Процесс взаимодействия концентрированных потоков энергии с металлами достаточно изучен, но вопросы о влиянии теплофизических свойств используемых материалов на процессы кристаллизации требуют дополнительного изучения. Целью данной статьи является физико-математическое моделирование процесса кристаллизации ванны расплава, полученной при воздействии лазерного и электронного лучей на материал покрытия.

Для достижения указанной цели поставлены и решены следующие задачи исследования: решена задача Стефана о затвердевании расплава; найдены зависимости положения фронта кристаллизации и скорости его перемещения от времени, скорости кристаллизации от теплофизических параметров материала покрытия, скорости кристаллизации в двойных и тройных системах Fe-Ni, Fe-Cr, Fe-Ti, Fe-V, Fe-W, Fe-Ni-Cr, Fe-Ni-Ti, Fe-Ni-V, Fe-Ni-W от процентного содержания компонентов; построена физическая модель кристаллизации ванны расплава, полученной при воздействии лазерного и электронного луча на материал покрытия.

В процессах, сопровождающих обработку материалов, существенное значение имеет определенный класс тепловых задач, связанных с фазовым переходом на некоторой границе раздела, положение которой неизвестно и должно быть определено из решения задачи. К этим задачам относятся процессы плавления и последующего затвердевания расплавов, связанные с воздействием концентрированных источников тепла. Указанные задачи обычно объединяются под общим названием задачи Стефана [1]. В задаче Стефана находится распределение температуры в фазах (твердой и жидкой) и положение границы фазового перехода с течением времени. Математическая формулировка задачи о затвердевании жидкой фазы имеет вид

$$
\begin{gathered}
\frac{1}{a_{1}} \frac{\partial T_{1}}{\partial t}=\frac{\partial^{2} T_{1}}{\partial x^{2}} ; \quad \frac{1}{a_{2}} \frac{\partial T_{2}}{\partial t}=\frac{\partial^{2} T_{2}}{\partial x^{2}} ; \\
\mathrm{T}_{2}(\infty, \mathrm{t})=\mathrm{T}_{\mathrm{o}} ; \mathrm{T}_{1}(0, \mathrm{t})=0 ; \mathrm{T}_{1}=\mathrm{T}_{2}=\mathrm{T}_{\mathrm{m}} ; \lambda_{1} \frac{\partial T_{1}}{\partial x}-\lambda \frac{\partial T_{2}}{\partial x}=\left.\gamma L_{m}\right|_{x=X(t)} .
\end{gathered}
$$

Решение задачи записывается соотношением

$$
\frac{\exp \left(-\chi^{2}\right)}{\operatorname{erf}(\chi)}-\frac{\lambda_{2} \sqrt{a_{1}}\left[\left(T_{o} / T_{m}\right)-1\right] \exp \left(-\frac{a_{1} \chi}{a_{2}}\right)}{\lambda_{1} \sqrt{a_{2}} \operatorname{erfc}\left(\chi / \sqrt{\frac{a_{1}}{a_{2}}}\right)}=\frac{\chi L_{m} \sqrt{\pi}}{c_{1} T_{m}},
$$

где $\mathrm{c}_{1-}$ теплоемкость твердой фазы; $\lambda_{1}, \lambda_{2}$ - теплопроводность твёрдой и жидкой фаз соответственно; $\mathrm{a}_{1}$ и $\mathrm{a}_{2}$ - температуропроводность твёрдой и жидкой фаз соответственно; $\mathrm{L}_{\mathrm{m}}$ - удельная теплота плавления; $\mathrm{T}_{0}$ и $\mathrm{T}_{\mathrm{m}^{-}}$температура расплава и температура плавления металла; $\chi=k / \sqrt{a_{1}}, X=2 k \sqrt{t}$-положение границы фазового превращения.

Таким образом, для построения физико-математической модели кристаллизации расплава необходимо решить данное уравнение [1]. Уравнение, описывающее решение задачи Стефана о затвердевании расплава, решалось методом половинного деления [2]. В качестве материала покрытия использовались переходные металлы: (железо, никель, хром, титан, ванадий, вольф- 
рам), так как они являются основными составляющими современных сплавов. Расчёты проводились как для отдельных компонентов, так и для их двойных и тройных соединений, для которых предварительно были рассчитаны теплофизические характеристики (тепло- и температуропроводность, теплоёмкость, удельная теплота плавления и т.д.) в зависимости от процентного соотношения компонентов в исследуемой смеси.

Данная задача решалась в программной среде Excel. Метод половинного деления дал возможность определить корень этого уравнения $\chi$ с достаточной степенью точности. На основании полученных результатов построены зависимости положения фронта кристаллизации и скорости кристаллизации от времени по формулам $X=2 \chi \sqrt{a_{1} t}, v=\frac{\chi a_{1}}{\sqrt{a_{1} t}}$ (рис. 1 и 2):.

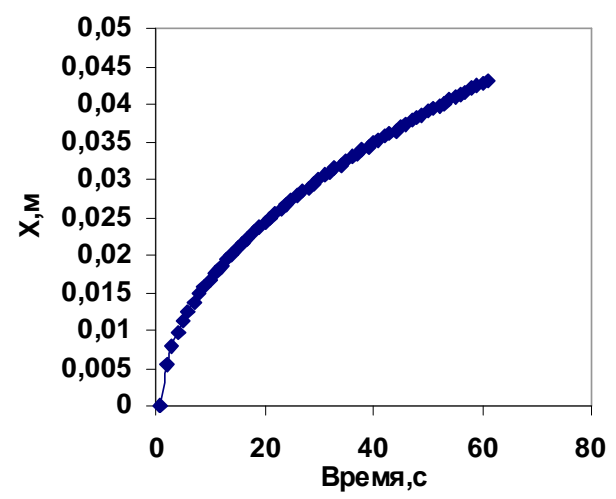

Р и с. 1. Положение фронта кристаллизации в никелевой ванне расплава

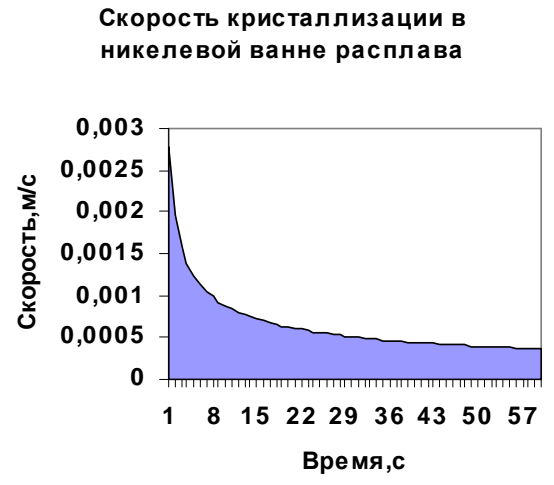

Р и с. 2. Зависимость скорости кристаллизации в никелевой ванне расплава от времени

Из рис. 2 видно, что скорость кристаллизации ванны расплава со временем убывает: более резко вначале процесса, затем - плавнее. Это соответствует классической теории затвердевания: процесс кристаллизации вначале ускоряется, пока в какой-то момент взаимное столкновение растущих кристаллов не начнёт заметно препятствовать их росту; рост кристаллов замедляется, тем более, что и жидкости, в которой образуются новые кристаллы, становится всё меньше. При нагревании материала концентрированными потоками энергии- лазерным или электронным лучами- добавляется ряд факторов, влияющих на процесс кристаллизации. В отличие от традиционного формирования расплава, например в печи, когда происходит переплав всей массы металла, при лазерном формировании расплавляется только тонкий поверхностный слой. Следовательно, в этом случае теплоотвод происходит более интенсивно, так как сама обрабатываемая деталь является хорошим проводником тепла из зоны обработки в её глубь, что приводит к увеличению скорости кристаллизации. С течением времени тепло равномерно распределяется по всему материалу, что сказывается на уменьшении скорость кристаллизации.

На основании классической теории затвердевания расплава можно сде-

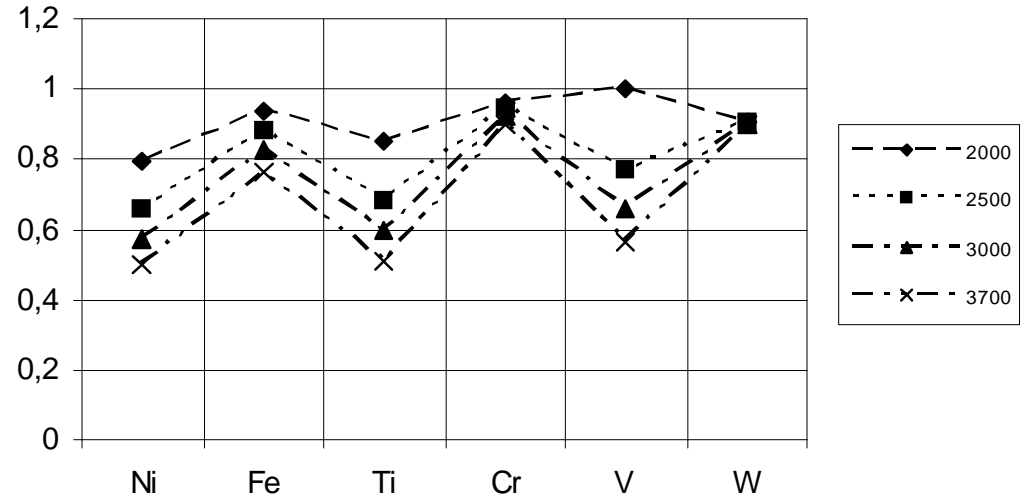

Р и с. 3. Скорость кристаллизации для никеля, железа, титана, хрома, ванадия, вольфрама при различных температурах ванны расплава лать вывод, что чем выше температура плавления обрабатываемого материала, тем скорость кристаллизации должна быть выше. Зависимость коэффициента $\chi$, который прямо пропорционален скорости кристаллизации, для ряда металлов (никель, железо, титан, хром, ванадий, вольфрам), расположенных в порядке возрастания температуры плавления, при различных температурах ван- 
ны расплава приведена на рис. 3. Из рис. 3 следует, что нет прямой зависимости между скоростью кристаллизации и температурой плавления металлов. Так титан и ванадий выпадают из этого ряда: скорость кристаллизации титана меньше, чем у железа, обладающего меньшей температурой плавления; у ванадия меньше, чем у хрома. Возможно, это связано с недостаточно точным измерением теплофизических постоянных при высоких температурах. В то же время, например, титан обладает большей по сравнению с другими рассматриваемыми металлами удельной теплотой плавления, т.е. при его кристаллизации выделяется большое количество теплоты, что и сказывается на уменьшении скорости кристаллизации.

При повышении температуры ванны расплава скорость кристаллизации для всех элементов уменьшается. Это связано с уменьшением числа нерасплавившихся кристаллов, являющихся центрами кристаллизации. У вольфрама скорость кристаллизации при любой температуре ванны расплава практически не изменяется и является высокой по сравнению с другими исследуемыми материалами. Это, несомненно, связано с очень большой температурой плавления вольфрама. Даже если теоретически получить расплав с температурой больше температуры плавления вольфрама (3700 К), то всё равно это практически не скажется на изменении скорости кристаллизации.

В двойных сплавах $\mathrm{Fe}-\mathrm{Ni}, \mathrm{Fe}-\mathrm{Ti}, \mathrm{Fe}-\mathrm{Cr}, \mathrm{Fe}-\mathrm{V}, \mathrm{Fe}-\mathrm{W}$ добавление титана и никеля понижает скорость кристаллизации соответственно на $10 \%$ и 18\%; хром и вольфрам - повышают (рис. 4). Ванадий, когда температура ванны расплава меньше его температуры плавления, значительно повышает скорость кристаллизации при увеличении его процентного содержания в двойных системах с железом. В тройных системах $\mathrm{Fe}-\mathrm{Ni}-\mathrm{Cr}$, Fe-Ni-Ti, Fe-Ni-V, Fe-Ni-W наблюдаются такие же закономерности (рис.5). Следовательно, изменяя состав исходной смеси, можно регулировать скорость кристаллизации, а значит изменять структуру и свойства формируемого покрытия.

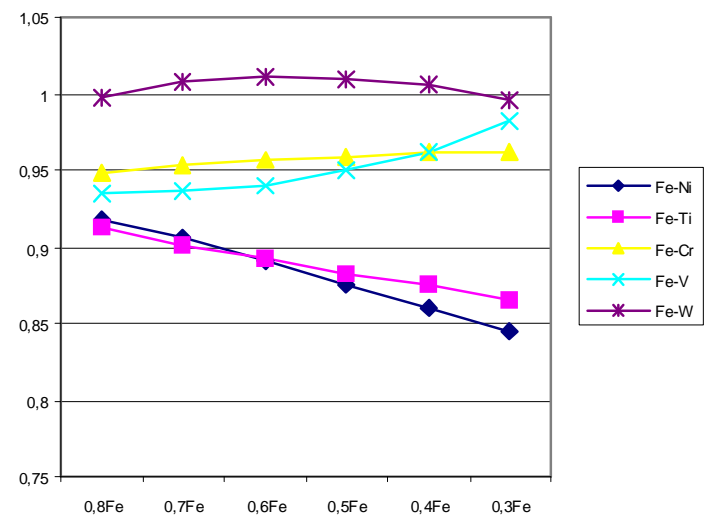

Р и с. 4. Зависимость скорости кристаллизации от процентного содержания компонетов в двойных системах при температуре ваннны расплава $2000 \mathrm{~K}$

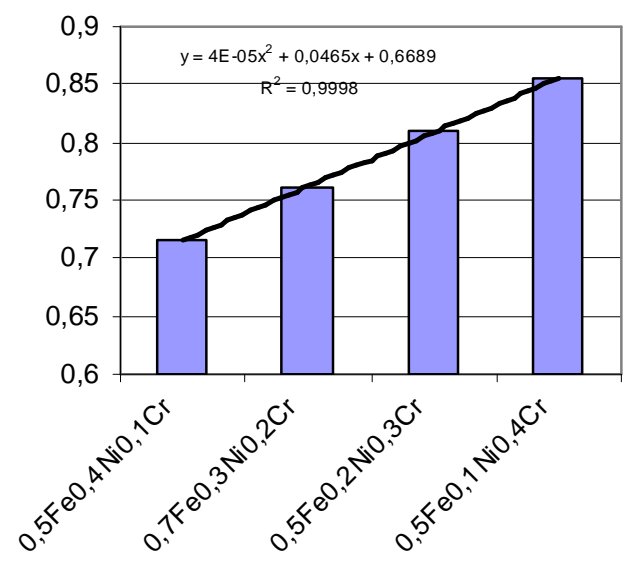

Р и с. 5. Зависимость скорости кристаллизации от процентного содержания компонентов в системе $\mathrm{Fe}-\mathrm{Ni}-\mathrm{Cr}$

Таким образом, на основе полученных результатов можно построить следующую модель процесса кристаллизации расплава, сформированного концентрированными потоками энергии. После расплавления материала на некоторую глубину происходит его остывание за счёт теплообмена со стенками, дном ванны расплава и с окружающим воздухом. Процесс кристаллизации начинается у дна и стенок ванны. Центрами кристаллизации являются также тугоплавкие частицы, присутствующие в расплаве. На первом этапе процесс кристаллизации происходит интенсивно, так как разность температур между расплавленным металлом и стенками достаточна велика. В связи с этим на дне формируется структурно неоднородное покрытие. При приближении фронта кристаллизации к поверхности процесс кристаллизации замедляется, что способствует формированию более однородной структуры. В итоге сформированное покрытие имеет градиент свойств и структуры по глубине, что обусловлено не только особенностью нагрева концентрированными потоками энергии металлов, но и особенностью кристаллизации образованного расплава. Данная модель кристаллизации удовлетворительно описывает результаты эксперимента, описанные в работе [3]. 


\section{БИБЛИОГРАФИЧЕСКИЙ СПИСОК}

1. Ведёнов А.А., Гладуш Г.Г. Физические процессы при лазерной обработке материалов. М.: Энергоиздат, 1985. $207 \mathrm{c}$.

2. Демидович Б.П., Марон И.А. Основы вычислительной математики. М.: Наука, 1970.

3. Косинова С.Н. Изучение структуры и свойств покрытий на основе переходных металлов и их карбидов, полученных с помощью концентрированных потоков энергии: Автореф. дис. ... канд. физ. - мат. наук. Самаpa, 1998. $16 \mathrm{c}$ 